\title{
Un geranium humboldtii al jardí geogràfic. Opinió pública, burgesia i paisatge als inicis de la geografia moderna
}

\author{
Bernat Lladó Mas \\ Col-lectiu (Sa)badall. Grup de Geografia i Gènere. Universitat Autònoma de Barcelona \\ bernat.1lado@gmail.com
}

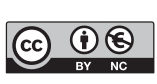

Recepció: juny de 2012

Aceptació: desembre de 2012

\section{Resum}

Alexander von Humboldt (1769-1859) fou un personatge central de la vida europea entre els segles XVIII i XIX. La seva obra escrita, que va des de la botànica fins a l'economia política, passant per la geografia i la geologia, permet seguir l'evolució del coneixement científic i filosòfic durant el període il.lustrat i romàntic. Alguns dels seus escrits generen, encara avui en dia, certa controvèrsia, en la mesura que s'han interpretat com un exemple clar d'allò que alguns autors anomenen la "presa indirecta del poder per part de la burgesia». En un moment històric en el qual el poder aristocràticofeudal encara era vigent a Europa, l'obra de Humboldt es pot llegir en clau revolucionària, és a dir, com un intent de despertar una nova consciència de classe a través del coneixement científic i geogràfic. Resseguir els passos i les estratègies de Humboldt ens pot ajudar a comprendre millor el rol que poden tenir la ciència i la filosofia en la formació d'un discurs crític.

Paraules clau: Alexander von Humboldt; revolució; burgesia; paisatge; naturalesa; cosmos; història del pensament geogràfic.

Resumen. Un geranium humboldtii en el jardin geográfico. Opinión pública, burguesía y paisaje en los inicios de la geografia moderna

Alexander von Humboldt (1769-1859) fue un personaje central de la vida europea entre los siglos XVIII y XIX. Su obra escrita, que va desde la botánica hasta la economía política, pasando por la geografía y la geología, permite seguir la evolución del conocimiento científico y filosófico durante el período ilustrado y romántico. Algunos de sus escritos generan, todavía hoy, cierta controversia, en la medida que se han interpretado como un ejemplo claro de aquello que algunos autores llaman la «toma indirecta del poder por parte de la burguesía». En un momento histórico en el cual el poder aristocrático-feudal aún era vigente en Europa, la obra de Humboldt se puede leer en clave revolucionaria, es decir, como un intento para despertar una nueva conciencia de clase a través del conocimiento científico y geográfico. Seguir los pasos y las estrategias de Humboldt nos puede ayudar a comprender mejor el rol que pueden tener la ciencia y la filosofía en la formación de un discurso crítico.

Palabras clave: Alexander von Humboldt; revolución; burguesía; paisaje; naturaleza; cosmos; historia del pensamiento geográfico. 
Résumé. Un geranium humboltdii dans le jardin géographique. Opinion publique, bourgeoisie et paysage dans les commencements de la géographie moderne

Alexandre von Humboldt (1769-1859) a été un personnage central de la vie européenne entre le XVIIIe et le XIXe siècle. Son œuvre écrite varie de la botanique à l'économie politique en passant par la géographie et la géologie. Au même temps, permet de suivre l'évolution de la connaissance scientifique et philosophique pendant le période des Lumières et du Romantisme. Certains de ses écrits génèrent encore aujourd'hui controverse, dans la mesure qu'ils ont été interprétés comme un clair exemple de cela que quelques auteurs ont nommé la prise indirecte du pouvoir pour la bourgeoisie. Dans un moment historique dans lequel le pouvoir aristocratique-féodal était toujours en vigueur en Europe, l'œuvre de Humboldt peut être lue en clé révolutionnaire, c'est-à-dire, comme une tentative pour réveiller une nouvelle conscience de classe à travers de la connaissance scientifique et géographique. Suivre les pas et les stratégies de Humboldt peut nous aider à une meilleure compréhension du rôle qui peut avoir la science et la philosophie dans la formation d'un discours critique.

Mots clé: Alexander von Humboldt; révolution; bourgeoisie; paysage; nature; cosmos; histoire de la pensée géographique.

Abstract. A geranium humboldtii in the geographical garden: Public opinion, bourgeoisie and landscape in early modern geography

Alexander von Humboldt (1769-1859) was a well-known figure in European society during the $18^{\text {th }}$ and $19^{\text {th }}$ centuries. His work concerned topics ranging from botany and political economy to geography or geology, thus reflecting the scientific and philosophical evolution of knowledge during the Enlightenment and the Romantic period. Many of his publications still generate some controversy in a way that has been interpreted as a clear example of what is sometimes called the indirect control of power by the bourgeoisie. In a historical moment in which the aristocratic-feudal power was still exerting its control over Europe, Humboldt's work can be seen as a revolutionary attempt to awaken a new class consciousness through scientific and geographical knowledge. Following Humboldt's steps, as well as his strategies, can help us to better understand the role science and philosophy play in forming a critical discourse.

Keywords: Alexander von Humboldt; revolution; bourgeoisie; landscape; nature; cosmos; history of geographical thought.

\section{Sumari}
1. Naturalesa
4. Cosmos
2. Paisatge
Referències bibliogràfiques

3. Viatge

Introduir-se a l'obra i la vida d'Alexander von Humboldt és una tasca certament desbordant. El seu interès gairebé obsessiu a estudiar-ho tot, a recopilar qualsevol informació i a escriure-la i transmetre-la al públic fa que la seva obra sigui pràcticament inabastable i la seva escriptura tendeixi a ser "voluminosa» $\mathrm{i}$ «inesgotable», pròpia del gest col-leccionista (Ette, 2004: 10). Si, a més, tenim 
en compte que ha generat i genera aquest «incessant polsim de discursos crítics» propis d'una obra clàssica (com el que aquí presento), i que la mateixa obra "s'expulsa contínuament de sobre», aleshores la tasca esdevé doblement feixuga (Calvino, 2009: 16). Resulta difícil posar ordre a tot el conjunt, intentar recórrer un fil que sigui coherent i que permeti donar sentit no només al seu treball intel.lectual, sinó també a la seva vida. No obstant això, em sembla que val la pena intentar-ho. Ho podem fer a partir de la idea de cosmologia tal com ha estat presentada pel filòsof Mario Bunge (2007). Per aquest autor, quan parlem de cosmologia, ho fem per referir-nos a una «visió sinòptica del món». Aquesta visió, la majoria de vegades, no és explícitament reconeguda, sinó que és tàcita. D'una manera més o menys clara, més o menys rígida, tots tenim una cosmologia, és a dir, una manera d'ordenar parts i fragments de la nostra realitat més immediata en el si d'un conjunt més ampli. Sense aquesta capacitat, el nostre món no tindria cap sentit. És la funció conceptual de les cosmologies. Però aquestes també tenen una funció pràctica: són una "guia per a la vida», és a dir, ens ajuden a "marcar-nos objectius, escollir mitjans, dissenyar plans i avaluar-ho tot plegat» (Bunge, 2007: 43-44).

Partint d'aquestes idees, podem mirar d'esbrinar quina va ser la «visió sinòptica del món» d'Alexander von Humboldt, la cosmologia tàcita dels seus treballs, allò que li facilitava una estructura on cada fet estudiat i cada idea pensada encaixaven i eren coherents entre si. Aquesta manera de plantejar el problema pot ser interessant, perquè matisa l'opinió segons la qual el geògraf del Cosmos era un empirista. Certament, donava molt de valor a l'observació i a l'experiència, però també és cert que tant l'una com l'altra estaven informades per prejudicis (no necessàriament negatius). El treball d'una geografia crítica pot ser el de revelar la cosmologia, manifesta o no, de qualsevol recerca empírica. En el cas de Humboldt, em sembla que existeixen quatre marcs fonamentals que configuren i que donen forma a la seva cosmologia; quatre idees rectores que descriuen la seva teoria geogràfica i que «guien» la seva recerca. Començaré per la idea de naturalesa (1); mostraré que aquesta idea el podria haver conduït a la de paisatge (2); seguidament, indicaré que el paisatge "exigeix» un viatge (3), i, finalment, conclouré amb el sentit del terme cosmos (4).

Alexander von Humboldt neix a Berlín l'any 1769, dos anys després que el seu germà Wilhelm. Si bé no pertanyen a una família aristocràtica, al llarg de la seva vida, els dos germans estaran vinculats de forma més o menys intermitent a la cort del rei de Prússia. Durant la infancia, reben una formació clàssica (un dels seus tutors, Gottlob Chistian Kunth, futur administrador del patrimoni familiar després de la mort de la mare l'any 1796, és un gran admirador de Jean-Jacques Rousseau). Més tard, freqüentaran els cercles liberals jueus de Berlín. El saló regentat per Henriette Herz serà, en aquest sentit, de gran importància (Arendt, 2004). Després de recórrer diferents universitats alemanyes, Alexander estudia a l'Acadèmia Minera de Freiberg. Això li permet obtenir un lloc de treball al Departament prussià de Mineria. Pocs mesos abans, havia fet 
un viatge determinant en molts aspectes. Juntament amb Georg Forster, figura clau en la història de la literatura científica i de viatges alemanya, Alexander havia viatjat fins a Londres a través del Rin. De tornada, els dos amics sojornen a París. Som a l'any 1790, i als carrers de la ciutat es viu encara l'euforia revolucionària. A partir d'aquest moment, cap dels dos abandonarà els ideals de la Revolució Francesa. Arran d'aquest viatge, Forster publicarà un llibre de gran importància per al jove Humboldt: Ansichten vom Niederrhein (Vistes del curs baix del Rin) (1791-94). Un llibre que també llegirà amb interès Johann Wolfgang von Goethe, amb qui Alexander mantindrà no només una gran amistat, sinó també una afinitat intel.lectual molt important.

El pare de Humboldt havia mort l'any 1779 i el 1796 mor la mare. Això precipitarà el curs de les coses. Alexander deixa la feina del Departament de Mineria, ha rebut una bona herència. Juntament amb el metge i botànic Aimé Bonpland, amb qui s'han conegut a París, Humboldt abandona la ciutat francesa en direcció a Marsella. Des d'aquí tenen plans de viatjar al nord d'Àfrica. La delicada situació política (l'any 1799 l'expedició napoleònica ha arribat a Egipte) retarda la partida. Per això decideixen canviar el destí de les seves vides. Resseguint la costa francesa en direcció al sud, passen a la península Ibèrica. Objectiu: aconseguir el vistiplau del monarca espanyol a fi de poder viatjar a les colònies americanes.

\section{Naturalesa}

La naturalesa no és un objecte neutre. És una construcció social i cultural. No en el mal sentit que no existeix sense la cultura, sinó que el seu interès, el seu significat, el grau de simbolització o la manera d'estudiar-la i d'observarla canvia al llarg del temps i varia d'una cultura a una altra. Partint d'aquest supòsit, que no és nou ni propi, pot ser interessant preguntar-se quina és la idea de naturalesa subjacent a l'obra filosòfica i geogràfica de Humboldt. Alguns autors el situen, d'entrada, en el moviment cientificofilosòfic conegut amb el nom de neovitalisme (Heinz, 1999).

Aquest moviment es difongué durant el segle XVIII a Alemanya a partir, sobretot, de la Universitat de Göttingen. Durant el curs 1789-1790, Humboldt havia estudiat en aquest centre, on, a part de conèixer Georg Forster, s'havia familiaritzat amb les idees i els debats sobre la naturalesa que hi tenien lloc. Segons aquest corrent de pensament, la naturalesa s'havia de concebre com un tot interrelacionat, complex, dinàmic i viu, mogut per forces internes i externes. El tot no es podia entendre simplement com la suma de les seves parts. Avui en dia, que ja hem assumit un punt de vista sistèmic, diríem que el tot té propietats emergents, és a dir, propietats inèdites que no posseeixen les diferents parts del tot per si soles. D'aquesta manera, es postulava certa idea d'unitat, d'harmonia, darrere l'aparent multiplicitat i diferència dels fets naturals. En aquest sentit, el concepte de fisonomia utilitzat per Humboldt per descriure la unitat d'un paisatge es pot entendre en aquesta direcció. L'havia manllevat del teòleg suís Johann Kaspar Lavater, per qui el caràcter d'una 
persona es podia deduir del seu rostre. Humboldt ho trasllada a la realitat paisatgística, per això avui utilitzem encara metàfores com ara la «identitat» d'un paisatge, la seva "personalitat» o el seu «caràcter», el seu «rostre» o la seva «pell». Pau Vila encara escriurà aquella magnífica monografia sobre la «fesomia geogràfica de Catalunya» (Vila, 1937).

L'any 1789, Humboldt havia visitat el gabinet de curiositats del doctor Gottfried Christoph Beireis (Blumenberg, 2000: 287). Aquesta experiència el deixà completament trasbalsat: quina imatge més patètica oferia una naturalesa morta, exposada, dissecada i descontextualitzada! A partir d'aquell moment, Humboldt entendrà que la representació de la naturalesa ha de ser tan viva com la mateixa naturalesa. De fet, el gabinet de Beireis era coherent amb una "concepció genèrica de la naturalesa» — tal com deia Cassirer-, és a dir, amb la idea d'una naturalesa estàtica, rígida, agrupada i dividida en espècies i gèneres (Cassirer, 1944). Certament, a l'època de Humboldt i Beireis, existien visions alternatives a la fragmentació i a la multiplicitat: la filosofia de la naturalesa d'un Schiller o un Hegel també buscava aquesta idea unitària de la naturalesa, i la imatge mecanicista d'un univers reductible a alguns principis generals també anava més enllà d'una realitat sensiblement heterogènia. Cap d'aquestes alternatives, però, convencien Humboldt.

Segurament, el neovitalisme era més afí a la literatura romàntica del moment, i Humboldt tenia, als prestatges de la seva biblioteca, tant La Nova Elö̈s (1761), de Rousseau, com Pau i Virgínia (1787), de Bernardin de Saint-Pierre. Sens dubte, tots dos també influïren en la idea de naturalesa del geògraf prussià. El Rousseau més sentimental ja no observa la naturalesa com un espectacle, sinó que tradueix una nova relació afectiva amb l'entorn natural. Es veu agitat i commocionat pels ritmes de la naturalesa, s'abandona a les «mil impressions amb les quals [aquella] ens obsequia incessantment» i que són la base del seu goig i de la seva veritable comprensió (Cassirer, 1932: 106, 131).

Jean-Marc Besse ha estudiat amb detall la diferència entre l'ascensió de Petrarca al Mont Ventós i l'ascensió de Rousseau sobre la vall alta del Roine («Lettere sur le Valais», a La Nova Eloïsa). Si bé la intenció inicial és la mateixa (la purificació moral, el camí d'una regeneració espiritual vers una vida més plena i autèntica), l'experiència resultant serà del tot diversa. Pel primer, escriu Besse, «la vista des del cim comporta només un examen de consciència» (Besse, 2010: 31). La distància entre la certesa interior i la realitat sensible és encara massa gran perquè Petrarca pugui gaudir del paisatge. Rousseau, en canvi, aconsegueix oblidar-se de si mateix i, d'aquesta manera, aboleix la distància entre el jo i les coses externes (Besse, 2010: 31). És com si Petrarca fos un dels primers a atrevir-se a obrir la finestra de la cultura occidental per mirar enfora, però per tancar-la immediatament després: la consciència interior cristiana és encara massa rica per distreure-la. Rousseau, contràriament, obre la finestra de bat a bat per abandonar-se a les «mil impressions» del paisatge; des d'aleshores ja no l'hem tancat. Humboldt formarà part, doncs, d'aquesta cultura de les vedute que inaugura, entre d'altres, Rousseau. 
Finalment, la naturalesa humboldtiana també té l'origen en la filosofia de Herder i en la de Goethe. Les Idees per a la filosofia de la història de la Humanitat del primer començava, de fet, amb un passatge de la Història natural de Plini, segons la qual la força i la grandesa de la natura no podien ser observades per qui no la copsés en la seva totalitat i es limités, en canvi, a considerar-ne només una part o més; justament, el mateix passatge seleccionat per Humboldt a l'hora d'obrir el Cosmos (Farinelli, 1998: VII ). Amb Goethe, la influència serà encara més evident. Tots dos participaran en aquesta mutació general que entén la naturalesa no com una cosa rígida, sinó "genètica» i dinàmica (Cassirer, 1944). El concepte de "morfologia» de Goethe és, en aquest sentit, cabdal per entendre aquest trànsit; un concepte, per cert, que alguns autors han relacionat estretament amb el de fisonomia. No és estrany, doncs, que Humboldt li dediqués la versió alemanya del seu Assaig de la geografia de les plantes (1807) (Gómez i Sanz, 2010: 33). Així mateix, els dos autors compartien la idea central d'una harmonia de la naturalesa. Fet i fet, el projecte general del geògraf fou comprovar empíricament aquesta idea rectora (Capel, 1981: 8).

És a partir d'aquest context que pot sorgir la idea neovitalista d'una naturalesa harmònica, interrelacionada i complexa. Aquest, però, no és l'únic significat que Humboldt atribueix a la naturalesa. Tot just al començament del Cosmos, hi podem llegir: "La naturalesa és el regne de la llibertat» (Humboldt, 2011: 6). Com podem interpretar això? Immediatament, ens ve al cap el comentari que Hanno Beck fa dels Quadres de la naturalesa, obra publicada l'any 1808 i reeditada i revisada successivament pel mateix Humboldt. Diu el biògraf que l'obra s'edità per tal d'aixecar els ànims deprimits del poble prussià per mitjà de la contemplació de la naturalesa «lliure» («A les muntanyes, hi ha la llibertat!») (Beck, 1971: 258). Dos anys abans, un 25 d'octubre, Napoleó havia entrat a Berlín. Prússia estava ocupada.

Ara bé, més enllà d'aquestes circumstàncies històriques, aquesta idea d'una naturalesa lliure també seria l'expressió de «l'humanisme actiu» de Humboldt. Per aquest, l'estudi de la naturalesa no pot ser mai un fi en si mateix, sinó que ha de ser un mitjà per promoure la humanitat (el «subjecte moral», en paraules de l'època) i la llibertat democràtica (Beck, 1987: 321). Si fins ara Humboldt seguia indirectament el Rousseau més romàntic, la teoria educativa implícita en aquest humanisme deixa respirar el Rousseau republicà. L'únic camí vers un nou contracte social depenia del fet que la «voluntat general» (el poble) estigués ben instruïda. En aquest sentit, la geografia i les ciències naturals formaven part d'aquesta instrucció. Per això Humboldt finançà directament, entre altres coses, l'Escola Lliure de Mineria l'any 1793, al poble de Steben. L'assistència a l'escola era voluntària i lliure. S'hi ensenyaven nocions de geologia, mineralogia, legislació minera, geografia i matemàtiques (Botting, 1981: 26).

Amb tot, és possible ajustar encara més la resposta, perquè aquesta «llibertat» podria vincular-se no només al conjunt de la humanitat, sinó també a un subjecte històricament concret i determinat: la burgesia, que, en aquell moment, començava a tenir una clara consciència d'ella mateixa. Per entendre això, introduiré el concepte de paisatge. 


\section{Paisatge}

Malgrat la particular i ambivalent situació psicosocial d'Alexander von Humboldt, en la mesura que, al llarg de la seva vida, fou un portaveu dels ideals revolucionaris burgesos i, al mateix temps, depengué, per raons familiars, diplomàtiques $\mathrm{i}$ econòmiques, de la cort prussiana (sense tenir en compte les també conflictives relacions amb Napoleó i la monarquia espanyola), alguns autors han suggerit que el seu discurs científic formava part d'una estratègia burgesa per fer una presa indirecta del poder polític (Farinelli, 1998, 1999; Minca, 2007).

Amb Georg Forster compartien, a més de l'interès científic, la mateixa passió política. Tot i això, els dos personatges assoliren un compromís diferent en relació amb la "causa» burgesa. El primer fou un dels fundadors de la República de Magúncia entre gener i juliol de 1793. El segon, en canvi, participà i prengué part en la Revolució per mitjà del que el geògraf Franco Farinelli anomena «enginyeria cientificosocial» i l'historiador Reinhart Koselleck, la «marrada de l'art» (Farinelli, 1998; Koselleck, 2007). Possiblement, l'estratègia o el «compromís de Humboldt», «l'argúcia del paisatge», tenia el seu origen en el curs 1789-1790 a Göttingen. Durant aquells anys, tenia lloc a la Universitat un gran debat entre els "geògrafs d'estat» i els "geògrafs purs o naturals», que Hanno Beck ha simplificat de la manera següent: «La geografia, s'havia de limitar a descriure espais tancats en fronteres polítiques que representaven estats? No existia la possibilitat, per ventura, de cenyir-se a les divisions naturals, tal com ja ho havia entès PolyKarp Leyser, de Helmstedt?» (Beck, 1971: 34).

Introduint el paisatge en el si del discurs científic i geogràfic, Humboldt no només prenia part a favor dels geògrafs naturals, sinó que també duia a terme una revolució política a través dels instruments propis de la cultura. El mateix Hanno Beck ha escrit que "allò que a França s'havia aconseguit de fet", és a dir, la presa de la Bastilla, «només era possible a Alemanya en el terreny de les idees» (Beck, 1971: 82). I aquest terreny era el de l'opinió pública, la llei específicament burgesa segons John Locke, i que en aquest moment comença a consolidar-se i articular-se al voltant dels salons, els cafes, la república de les lletres, les societats secretes o les lògies francmaçones (Koselleck, 2007). Justament en aquesta nova esfera civil, crítica i burgesa, els filòsofs, artistes, banquers, editors, comerciants o il.lustrats estaven ja familiaritzats amb el paisatge, és a dir, amb la contemplació estètica de la naturalesa. Feia més d'un segle que la pintura de paisatges s'havia institucionalitzat com a gènere pictòric.

Alexander von Humboldt aprofita que el concepte estètic del paisatge circula entre els cercles il-lustrats per introduir-lo, per traspassar-lo i fer-lo migrar de la teoria de l'art i la pràctica artística al discurs científic i geogràfic (PuigSamper i Rebok, 2003; Ortega, 2006). D'aquesta manera, realitza una doble jugada: d'una banda, introdueix, en el si de la geografia, una imatge que va més enllà dels límits i les fronteres dels estats aristocraticofeudals; de l'altra, fa lliscar sobre l'opinió pública burgesa un significat inèdit del terme paisatge que escapa a la pura contemplació desinteressada de la naturalesa, a fi d'assegurar 
un nou coneixement capaç d'establir un domini i un control sobre el món. És en aquest sentit que els passatges següents esdevenen clarividents:

El secret polític de la Il-lustració consistia en el fet que tots els seus conceptes — de manera anàloga a la presa indirecta del poder - eren apolítics de manera invisible. En l'anonimat polític de la raó, de la moral, de la naturalesa, etc. radicava la seva singularitat $\mathrm{i}$ la seva eficiència característica. El seu valor polític consistia, precisament, a ser apolític. (Koselleck, 2007: 131)

Amb Humboldt, el pensament d'Occident completa per fi la conquesta pacífica i annexa idealment al seu món, el Cosmos únic, aquestes regions que fins aleshores només havien estat objecte de curiositat, d'estupor o de burla. (Antonello Gerbi, citat a Louise Pratt, 2010: 262)

Si el paisatge pot tenir aquest rol estratègic en el discurs de Humboldt és, justament, perquè és aparentment apolític; permet «annexar idealment», és a dir, en el terreny de les idees i de forma pacífica, indirecta, el món, convertit ara en l'espai de llibertat burgesa. Però les coses són sempre una mica més complicades. El paisatge no és només, en el cas de Humboldt, una estratègia política i molt menys un objecte o un conjunt d'objectes; és una teoria cognitiva (Farinelli, 2009: 44-45).

En un primer moment, ens sentim impressionats pel paisatge; es tracta de l'impacte sensorial que ens produeix la seva imatge global. El terme tècnic utilitzat per Humboldt és «impressió total», una expressió que hauria extret, directament o indirecta, del món de l'art. A la seva Investigació sobre la perfecció última en les obres de la pintura paisatgistica, publicat l'any 1800, Semler utilitza aquesta expressió per referir-se a la composició general d'una pintura de paisatge, contraposant-la als detalls particulars. I més tard, C.L. Fernow, en el tractat Sobre la pintura paisatgistica (1806), identifica la impressió total amb la concordança d'elements diversos (Misch, 2008: 285). Amb aquesta impressió estètica, es desencadena tot el procés de coneixement. Seguidament, en el segon estadi, s'abandona la idea de totalitat per començar-ne l'anàlisi de les parts per mitjà de la dissecció i la mesura, la recollida d'informació i l'inventari. Finalment, a la darrera fase, es restableix la globalitat original per mitjà de la síntesi, per tal d'entregar al públic una «imatge» o un "quadre» que no és subjectiu, sinó transparent i científic, és a dir, capaç de generar en el lector la mateixa impressió que experimentaria si estigués efectivament davant la naturalesa. D’aquesta síntesi, en diem «cosmos».

Aquest esquema tripartit del coneixement geogràfic (impressió total del paisatge, anàlisi i recollida d'informació, síntesi en un cosmos) és interessant, perquè, al mateix temps, ens ajuda a descriure les grans etapes vitals i científiques del mateix Humboldt. Existeix una curiosa homologia entre recerca científica i experiència viscuda. D'aquesta manera, un jove Humboldt hauria quedat impressionat no només pel paisatge de la seva Prússia natal, de les ribes del Rin durant el viatge amb el seu amic Forster o dels cims nevats d'Itàlia del nord o Suïssa (de juliol a novembre de 1795), sinó també per les descripcions literàries del mateix Forster, Daniel Defoe i Bernardin de Saint-Pierre, entre d'altres, 
o les pintures de William Hodge fetes durant el seu viatge a l'Índia. Més tard, la recepció d'aquesta literatura i l'experiència directa haurien despertat en Humboldt la curiositat per la naturalesa, per estudiar-la i analitzar-la. Això implicaria un viatge que, en el cas de Humboldt, és real, però que també podria ser metaforic, és a dir, un mètode (etimològicament, un recorregut, un camí) que permeti el treball empíric, la recopilació, l'observació i la comparació. Finalment, trobaríem un Humboldt reposat, vell, que hauria reordenat, en una síntesi nova, tot el material per donar-li forma, amb la qual cosa es passaria del caos al cosmos.

Després d'aconseguir, per mediació de Don Mariano Luis de Urquijo, aleshores primer ministre de la monarquia espanyola, el permís reial de Carles IV per viatjar a les colònies americanes i d'haver aixecat, d'un dia per l'altre, uns quants metres per sobre el nivell del mar els camps de Castella, Humboldt i Bonpland surten, el cinc de juny de 1799, del port de la Corunya en direcció a Tenerife, primera parada del seu viatge transatlàntic. Objectius: comprovar si existeix o no un canal natural que connecti els dos sistemes fluvials més importants de Sud-Amèrica, el de l'Amazones i el de l'Orinoco; observar l'estat de l'explotació minera de les colònies espanyoles; seguir els passos de Malaspina i La Condamine; estudiar la direcció dels grans estrats geològics de la serralada dels Andes, aclarir si el seu origen és neptunià o volcànic i observar la influència del clima en la distribució de les plantes i els animals, és a dir, «Prendre el pols del cel i la Terra» (Botting, 1981: 57). El dia 16 de juliol, arriben a Cumanà (actual Veneçuela); d'aquí viatgen a Caracas, que en aquest moment és un important centre revolucionari, pàtria dels Miranda i dels Bolívar, entre d'altres. Des de San Fernando de Apure, comencen a remuntar l'Orinoco. Entre el 10 i el 23 de maig de 1800, naveguen ja pel Casiquiare, el canal natural que uneix l'Amazones i l'Orinoco. Retornen seguint pràcticament el mateix itinerari; aquesta vegada amb el corrent a favor fins a Angostura; d'aquí a Nova Barcelona. Fi de la primera part del viatge. Des de Nova Barcelona viatgen per mar fins a Cuba i d'aquí, també per mar, a Cartagena. Inicien l'exploració de la serralada dels Andes. El mes de juliol de 1801, arriben a Bogotà, on els espera el botànic José Celestino Mutis. El mes de setembre són a Quito; coneixen José de Caldas i pugen al Pichincha i al Chimborazo. Franquegen els Andes en direcció al vessant occidental. Des de Callao, ressegueixen la costa peruana fins a Guaiaquil; Humboldt mesura sistemàticament la temperatura de l'aigua $\mathrm{i}$ "descobreix» el corrent fred que més tard portarà el seu nom. L'11 d'abril de 1803 , ja són a la ciutat de Mèxic, on sojornen un any sencer. Després de passar de nou per l'Havana, Humboldt i Bonpland viatgen fins a Filadèlfia, que, en aquest moment, ha perdut la capitalitat dels Estats Units, però manté encara un gran dinamisme cultural. Allà coneix el president Thomas Jefferson. El 9 de juliol de 1804, els dos científics surten de Filadèlfia i arriben de nou al vell continent el dia 3 d'agost. Resultat: "la primera enciclopèdia americana» (Díaz, 1991: 38). 


\section{Viatge}

El viatge forma part de la història i la teoria del paisatge. En el cas de Humboldt, és aquest pas intermedi abans de fer el treball de figuració d'una imatge sintètica i global de la naturalesa, un cosmos. Però el viatge a les colònies espanyoles d'Amèrica també té una dimensió històrica concreta. Fins a quin punt Humboldt parteix de la Corunya amb una imatge preestablerta d'Amèrica, amb un prejudici que no és només personal, sinó també eurocèntric?

Com ja s'ha indicat, la literatura romàntica tingué un pes rellevant en l'imaginari europeu de l'època. Els tròpics eren un dels seus topos comuns. El mateix Robinson Crusoe, de Daniel Defoe, escrit l'any 1719, tenia un títol prou suggeridor: Vida i meravelloses aventures de Robinson Crusoe, mariner de York, que durant 28 anys visqué totalment solitari en una illa deshabitada, davant la costa americana i a prop de la desembocadura del gran Orinoco. Per alguns autors, la novel.la de Defoe era una «fantasia de poder sobre la naturalesa» o, fins i tot, una "espècie d'al-legoria de l'imperi o de la modernitat mateixa» (Claeys, 2011: 88). També és cert que Humboldt estava prou familiaritzat amb tota la literatura pseudoutòpica de les primeres cròniques espanyoles per escriure'n un llibre (Examen crític de la història de la geografia del Nou Continent, París, 1814-34). En aquestes cròniques, sovint s'hi reproduïa la imatge d'Amèrica com una Arcàdia o un Edèn. De fet, un dels objectius principals del mateix Colom era trobar el paradís terrenal, fet que estava convençut d'haver assolit durant el seu tercer viatge quan es va trobar a la desembocadura del riu Orinoco (Barrientos, 1986). Des de la crítica postcolonial, Humboldt, més que descriure la realitat americana, hauria «reinventat» o «reforçat» la seva imatge ideològica; formaria part d'una tradició cultural europea que hauria vist el Nou Món com una naturalesa primordial, «un espai intemporal i no reclamat, ocupat per plantes i criatures vivents (algunes de les quals eren éssers humans), però sense cap organització social ni econòmica». Si el paisatge podia ser un instrument culturalment revolucionari a Europa, en el cas de la Relació Històrica, més aviat «desterritorialitzava els pobles indígenes, separant-los dels seus territoris que algun cop dominaren i on seguiren fent la seva vida» (Louise Pratt, 2010: 239, 252).

Humboldt i Bonpland han desembarcat a Bordeus el 3 d'agost de 1804. A pesar de l'ambigua relació amb Napoleó, Humboldt decideix quedar-se a París. Sap que la vida social i científica en aquesta ciutat és més important que a Berlín. Aquí podrà editar la seva obra més facilment. Tot i la frenètica activitat intel-lectual, també tindrà un paper destacat com a diplomàtic. El 14 d'abril de 1827, abandona finalment París. El mateix any, comença a donar la sèrie de conferències que finalment seran la base del Cosmos. Aquestes conferències, totalment gratuïtes, es convertiran en tot un esdeveniment social: aplegaran un públic heterogeni de fins a mil persones, i per això hauran d'habilitar la sala més gran disponible aleshores a Berlín. Aquestes conferències significaren la fi del romanticisme (Blumenberg, 2000). 


\section{Cosmos}

L'obra Cosmos: Assaig d'una descripció física del món es publicà successivament en diversos volums entre 1845 i 1862. No només representa l'obra de maduresa de Humboldt, sinó també el darrer estadi cognitiu de la seva teoria del paisatge, el restabliment de la unitat i l'harmonia de la naturalesa. No vull ser culturalment determinista, però em sorprèn la coincidència següent entre llengua nacional i discurs científic. Leo Spitzer afirma que, a les societats postil.lustrades, als principals idiomes europeus, els falta un terme que expressi «la unitat de sentiments experimentats per l'home i la dona davant el seu entorn (un paisatge, la naturalesa, un altre ésser humà) i que comprengui i soldi el que és objectiu (factic) amb el que és subjectiu (psicològic) en una unitat harmoniosa». Per aquest filòleg de la semàntica històrica, l'única llengua que hauria conservat aquesta idea d'harmonia i unitat hauria estat l'alemanya, a través de la paraula stimmung (Spitzer, 2008: 13). Potser no és tan estrany que el darrer esforç (segurament inútil) per representar un cosmos provingués, doncs, d'un geògraf alemany.

El dia 11 de maig de 1859, Humboldt és enterrat a la finca familiar de Schloss Tegel. Dos anys abans, Prússia, a petició del mateix Humboldt, havia aprovat una llei per abolir l'esclavitud. Qualsevol persona que trepitgés Prússia seria lliure.

\section{Referències bibliogràfiques}

AREndT, Hannah (2004). «Un salón berlinés». Revista de Occidente, 282, 105-116.

BARRIENTOS, Juan José (1986). «América, ese paraíso perdido: Disparidad de opiniones respecto a Colón». Humboldt/Goethe-Institut, no89, 18-23.

BeCK, Hanno (1971). Alexander von Humboldt. México: Fondo de Cultura Económica, 1959-61.

- (1987). «La geografia de Alexander von Humboldt». A: HeIn, Wolfgang-Hagen (ed.). Alexander von Humboldt: La vida y la obra. Berlín: C. H. Boehringer Sohn / Ingelheim am Rhein.

BESSE, Jean-Marc (2010). La sombra de las cosas: Sobre paisaje y geografía. Madrid: Nueva Visión.

Blumenberg, Hans (2000). La legibilidad del mundo. Barcelona: Paidós, 1981.

BotTing, Douglas (1981). Humboldt y el Cosmos: Vida, obra y viajes de un hombre universal (1769-1859). Barcelona: Ediciones del Serbal, 1973.

Bunge, Mario (2007). «Set paradigmes cosmològics: l'ànima, l'escala, el riu, el núvol, la màquina, el llibre i el sistema de sistemes». A: Bunge, Mario. Deu assaigs filosòfics i una diatriba exasperada. Barcelona: Documenta Universitària / Publicacions de la Càtedra Ferrater Mora, 43-60.

Calvino, Italo (2009). Por qué leer los clásicos. Madrid: Siruela, 2002.

CAPEL, Horacio (1981). Filosofía y ciencia en la geografía contemporánea: Una introducción a la geografía. Barcelona: Barcanova. Darrera reedició: CAPEL, Horacio (2012). Filosofía y ciencia en la geografía contemporánea: Una introducción a la geografía. Barcelona: Ediciones del Serbal. 
CASSIRER, Ernst (1932). «El problema Jean-Jacques Rousseau». A: CASSIRER, Ernst (2007). Rousseau, Kant, Goethe: Filosofía y cultura en la Europa del Siglo de las Luces. Madrid: Fondo de Cultura Económica, 49-155.

- (1944). "Goethe y la filosofia kantiana». A: CASSIRER, Ernst (2007). Rousseau, Kant, Goethe: Filosofia y cultura en la Europa del Siglo de las Luces. Madrid: Fondo de Cultura Económica, 233-279.

ClaEYs, Gregory (2011). Utopia: Historia de una idea. Madrid: Siruela.

DíAZ, Jesús (1991). "Alexander von Humboldt en los comienzos de un nuevo siglo». Humboldt/Goethe-Institut, 104, 36-39.

ETTE, Ottmar (2004). «Los caminos del deseo. Coreografías en la literatura de viajes: un ensayo acerca de su multidimensionalidad y figuras fundamentales de los movimientos que pone en escena». Humboldt/Goethe-Institut, 141, 10-14.

FARINELli, Franco (1998). «Il pappagallo degli Atures». A: HuMBOLDT, Alexander von (1998). Quadri della Natura. Florència: La Nuova Italia, VII-XXVI.

- (1999). "Text and Image in 18th and 19th-century German Geography: The witz of landscape and the astuteness of representation». A: ButTimer, Anne; BrunN, Stanley D. i WARDENGA, Ute (eds.). Text and Image: Social Construction of Regional Knowledges. Leipzig: Institut für LänderKunde, 38-44.

- (2009). «El don de Humboldt: el concepto de paisaje». A: COPETA, Clara i LoIs, Rubén (eds.). Geografía, paisaje e identidad. Madrid: Biblioteca Nueva, 43-49.

GÓMEZ, Josefina i SANZ, Concepción (2010). «De la biogeografía al paisaje en Humboldt: pisos de vegetación y paisajes andinos equinocciales». Población \& Sociedad, $17,29-57$.

HeInZ, Marion (1999). «La obra Cosmos de Alexander von Humboldt». Estudios de Filosofía, 19-20, 195-204.

Humboldt, Alexander von (2011). Cosmos: Ensayo de una descripción física del mundo. Madrid: Los Libros de la Catarata / CSIC, 1845.

KoselleCK, Reinhart (2007). Critica y crisis: Un estudio sobre la patogénesis del mundo burgués. Madrid: Trotta, 1969.

LOUISE PRATT, Mary (2010). Ojos imperiales. Literatura de viajes y transculturación. Mèxic: Fondo de Cultura Económica, 1992.

MincA, Claudio (2007). «Humboldt's compromise, or the forgotten geographies of landscape». Progress in Human Geography, 31 (2), 179-193.

MisCH, Jürgen (2008). «Ciencia y estética: reflexiones en torno a la presentación científica i representación artística de la naturaleza en la obra de Alexander von Humboldt». A: Cuesta, Mariano i ReboK, Sandra (coord.). Alexander von Humboldt: Estancia en España y viaje americano. Madrid: Real Sociedad Geográfica / CSIC, 279-297.

OrTEGA, Nicolás (2006). «Entre la explicación y la comprensión: El concepto de paisaje en la geografía moderna». A: MADERUELO, Javier (dir.). Paisaje y pensamiento. Madrid: Abada/CDAN, 107-129.

Puig-Samper, Miguel Ángel i ReboK, Sandra (2003). «Introducción: Alejandro de Humboldt y los "Cuadros de la Naturaleza"». A: HumboldT, Alejandro. Cuadros de la Naturaleza. Madrid: Los Libros de la Catarata.

SPITZER, Leo (2008). Ideas clásica y cristiana de la armonía del mundo. Madrid: Abada, 1963.

Vila, Pau (1937). La fesomia geogràfica de Catalunya. Barcelona: Comissariat de Propaganda de la Generalitat de Catalunya. 